\title{
INFRARED DRYING OF APRICOT POMACE
}

\author{
S. KAYRAN and İ. DOYMAZ ${ }^{\dagger}$ \\ $\dagger$ Chemical Engineering Department, Yildiz Technical University, Esenler, Istanbul, 34220, TURKEY \\ doymaz@yildiz.edu.tr
}

\begin{abstract}
Effect of infrared powers $(62,74,88,104$ and $125 \mathrm{~W}$ ) on drying kinetics of apricot pomace was investigated. It is observed that drying characteristics of apricot pomace were greatly influenced by infrared power. Henderson and Pabis model was investigated for describing thin-layer drying of apricot pomace. The model because of the high coefficient of determination $\left(R^{2}\right)$ as well as the lowest reduced chi-square $\left(\chi^{2}\right)$ and root mean square error (RMSE) values adequately described the experimental data of apple pomace drying. Effective moisture diffusivity $\left(D_{\text {eff }}\right)$ values were increased by increasing infrared power and changed between $1.67 \times 10^{-9}$ and $6.03 \times 10^{-9} \mathrm{~m}^{2} / \mathrm{s}$. Activation energy was estimated by a modified Arrhenius type equation and found to be $2.32 \mathrm{~kW} / \mathrm{kg}$. The colour results were affected by drying conditions.

Keywords-Apricot pomace, colour, effective moisture diffusivity, infrared drying, mathematical modelling.
\end{abstract}

\section{INTRODUCTION}

Losses in food production chain of agricultural products in general comprise these five steps: agricultural production stage, post-harvest processing and storage, food processing and packaging stage, which occurs in the distribution and consumption-stage (HLPE, 2014). Evaluation of food waste is of vital importance in terms of environmental impact and protection of natural resources. Rapid microbial spoilage due to the high-water content of food waste is the high transport and storage costs limit the opportunities of different assessment. The wastes are generally used in the some industry such as animal feed industry for animal feed and feed additives, the agricultural industry for manure and compost, food and pharmaceutical industries for the acquisition of functional compounds such as dietary fibre, pectin, unsaturated fatty acids, flavonoids, and also fuel production (Sui et al., 2014; Ribeiro et al., 2015; Stancu et al., 2016; Deamici et al., 2016).

Fruit juice industry has a large quantity of wastes, such as peel, seed, pomace, rags and kernels. In the apricot juice processing, the apricot pomace consists of pulp and apricot kernel. Ucuncu et al. (2013) reported that the apricot pomace contains $22 \%$ reduced sugar, mainly glucose and fructose, $1.29 \%$ protein, $14.6 \%$ total dietary fibre, and $0.79 \%$ ash.

Consumers pay attention to the use of high-quality products and new drying technology to reduce energy use, which will set the stage for competition to meet the demands of manufacturers on the market (Riadh et al., 2015). Sun drying is the most common technique used since ancient times. The transfer of heat energy by convection, conduction and radiation although three main methods; hot air convective drying technique is the most widely used method. Infrared drying has gained popularity as an alternative drying method for a variety of agricultural products. Infrared energy incident on the food material creates changes in electronic, vibrational and rotational states at atomic and molecular levels, without heating the surrounding air (Moses et al., 2014). Infrared drying could save up 50\% energy compared to convective drying (Chen et al., 2015). In recent years, it has become popular because of short drying time, high thermal efficiency and many advantages to obtain high quality products. Moreover, initial setup and the low operating costs, in the pre-drying stage by the drying process or the combined system is easy to integrate, applicable to ensure uniform temperature distribution at different wavelengths and power easy control of operating parameters. It also provides opportunities for different purposes such as short drying time, reduction of energy consumption, ensuring high thermal efficiency, good quality regardless of seasonal factors and good drying environment independent of tight spaces, pre-drying, drying, pasteurization, sterilization, baking, dissolving and roasting (Das et al., 2009; Motevali et al., 2011; Pawar and Pratepe, 2015).

The chemical and physical changes that occur during the drying process, the drying equipment and the drying method are important to understand the effect of the mathematical modeling of the microscopic nature of product moisture transfer. Thin-layer drying models can be categorized as theoretical, semi-theoretical and empirical. Various studies on mathematical modeling of fruit and vegetable pomace, by-product and waste are presented in the literature, including hot-air convective drying of apple, carrot, olive and watermelon pomaces (Wang et al., 2007; Kumar et al., 2012; Oberoi and Sogi, 2015), microwave drying of tomato pomace (AlHarahsheh et al., 2009), infrared drying of apple pomace, tomato by-product and grape pomace (Sui et al., 2014; Celma et al., 2009). However, there is no information about drying of apricot pomace with infrared radiation. The main objectives of this study were to investigate the effect of infrared power on the drying rate and time, fit the experimental data to ten thin-layer drying models, and compute effective moisture diffusivity of apricot pomace.

\section{MATERIALS AND METHODS}

\section{A. Sample Preparation}

Fresh apricot pomace were obtained from Döhler Fruit juice company in Karaman at June 2015 and kept in a refrigerator (Arcelik 1050T, Eskisehir, Turkey) at $4^{\circ} \mathrm{C}$ 
prior to use. The initial moisture content of the fresh apricot pomace was determined according to the method described by AOAC 934.06 (AOAC, 1990), was $4.6179 \mathrm{~kg}$ water / kg dry matter (d.b.).

\section{B. Drying Procedure}

Drying experiments were carried out in a moisture analyzer with one $250 \mathrm{~W}$ halogen lamp (Snijders Moisture Balance, Snijders b.v., Tilburg, Holland). In the infrared drying process, the sample should be separated evenly and homogeneously over the entire pan. The drying experiments were performed at infrared power level varying from 62 to $125 \mathrm{~W}$. The power level was set in control unit of equipment. Moisture loss in the samples with initial load of $75 \pm 0.2 \mathrm{~g}$ was measured with a digital balance (Mettler-Toledo AG, Grefensee, Switzerland, model BB3000) with accuracy of $0.1 \mathrm{~g}$ and recorded at $30 \mathrm{~min}$ intervals. Drying was stopped when the moisture content of samples was approximately $0.05 \mathrm{~kg}$ water $/ \mathrm{kg}$ dry matter (d.b.). The dried product was cooled and packed in low-density polyethylene bags that were heat-sealed. The experiments were triplicated.

\section{Mathematical Modelling}

The moisture content of apricot pomace was calculated by the following equation:

$$
M=\frac{W_{i}-W_{d}}{W_{d}}
$$

where $M$ is the moisture content ( $\mathrm{kg}$ water $/ \mathrm{kg}$ dry matter), $W_{i}$ is the weight of sample $(\mathrm{kg})$, and $W_{d}$ is the dry matter content of sample $(\mathrm{kg})$.

The moisture ratio $(M R)$ of the apricot pomace during drying experiments was calculated by using Eq. (2):

$$
M R=\frac{M_{t}-M_{e}}{M_{0}-M_{e}}
$$

where $M_{t}, M_{0}$ and $M_{e}$ are moisture content at any time, initial moisture content, equilibrium moisture content $(\mathrm{kg}$ water $/ \mathrm{kg}$ dry matter), respectively, and $\mathrm{t}$ is drying time (min). The equilibrium moisture content $\left(M_{e}\right)$ is relatively small compared with $M_{0}$, especially for infrared drying. Therefore, $M_{e}$ was numerically set to zero in this study. So $M R$ can be simplified to $M R=M_{t} / M_{0}$ (Fahloul et al., 2009; Calín-Sánchez et al., 2014).

The drying rate $(D R)$ was calculated using Eq. (3):

$$
D R=\frac{M_{t}-M_{t+d t}}{d t}
$$

where $M_{t+d t}$ is moisture content at $t+d t$ (kg water/kg dry matter) and $t$ is time (min).

Fick's second law of diffusion equation was used to fit the experimental drying data for the determination of effective moisture diffusivity coefficients.

$$
\frac{\partial M}{\partial t}=D_{e f f} \frac{\partial^{2} M}{\partial x^{2}}
$$

where $M$ is the moisture content (kg water/kg dry matter), $t$ is the drying time (s), $x$ is the distance in the solid (m), and $D_{\text {eff }}$ is the effective moisture diffusivity $\left(\mathrm{m}^{2} / \mathrm{s}\right)$.

The solution of diffusion Eq. (4) for slab geometry was solved by Crank (1975) and supposed uniform initial moisture distribution, negligible external resistance, constant temperature and diffusivity, and negligible shrinkage:

$$
M R=\frac{8}{\pi^{2}} \sum_{n=0}^{\infty} \frac{1}{(2 n+1)^{2}} \exp \left(-\frac{(2 n+1)^{2} \pi^{2} D_{e f f} t}{4 L^{2}}\right)
$$

where, $L$ is the half-thickness of sample $(\mathrm{m})$ and $\mathrm{n}$ is a positive integer. The Henderson and Pabis model is the first term of general series solution of Fick's second law of diffusion equation (Henderson and Pabis, 1961):

$$
M R=\frac{8}{\pi^{2}} \exp \left(-\frac{\pi^{2} D_{e f f} t}{4 L^{2}}\right) .
$$

Equation (6) can also be written in a more simplified form as:

$$
M R=a \exp (-k t) .
$$

\section{Data Analysis}

Data was analyzed using Statistica 8.0.550 (StatSoft Inc., Tulsa, OK, USA) software package. The parameters of model were estimated using a non-linear regression procedure based on the Levenberg-Marquardt algorithm. The fitting quality of the experimental data to the model was evaluated using the coefficient of determination $\left(R^{2}\right)$, reduced chi-square $\left(\chi^{2}\right)$, and root mean square error (RMSE). The $R^{2}, \chi^{2}$ and RMSE were calculated from the following formulas:

$$
\begin{gathered}
R^{2}=1-\frac{\sum_{i=1}^{N}\left(M R_{\text {pre }, i}-M R_{\text {exp }, i}\right)^{2}}{\sum_{i=1}^{N}\left(\overline{M R}_{\text {pre }}-M R_{\text {exp }, i}\right)^{2}} \\
\chi^{2}=\frac{\sum_{i=1}^{N}\left(M R_{\text {exp }, i}-M R_{\text {pre }, i}\right)^{2}}{N-z} \\
R M S E=\left[\frac{1}{N} \sum_{i=1}^{N}\left(M R_{\text {pre }, i}-M R_{\text {exp }, i}\right)^{2}\right]^{1 / 2}
\end{gathered}
$$

where $M R_{\text {exp }, i}$ and $M R_{\text {pre }, i}$ are experimental and predicted dimensionless moisture ratios, respectively, $N$ is number of observations, and $z$ is number of constants. The best model was chosen based on the highest value of $R^{2}$ and the least values of $\chi^{2}$, and RMSE (Chen et al., 2015).

\section{E. Computation of Activation Energy}

Activation energy $\left(E_{\mathrm{a}}\right)$ represents the minimum energy required for water molecules to migrate within the food during drying (Martynenko and Kudra, 2016). For the calculation of activation energy, modified form of Arrhenius equation as generally described in literature shows the relationship between the effective moisture diffusivity and the infrared power level to sample weight (Dai et al., 2015).

$$
D_{\text {eff }}=D_{0} \exp \left(-\frac{E_{a} m}{p}\right)
$$

where $D_{0}$ is the pre-exponential factor of Arrhenius equation $\left(\mathrm{m}^{2} / \mathrm{s}\right), E_{a}$ is the activation energy (W/kg), $p$ is the infrared power level (W) and $m$ is the sample weight $(\mathrm{kg})$. 


\section{F. Color Measurements}

Color measurements were taken on Minolta (Chroma Meter-CR-400 from Konica Minolta, Osaka, Japan) instrument. Total color change $(\Delta \mathrm{E})$ and Chroma $(\mathrm{C})$ were calculated the following equations (Adak et al., 2017).

$$
\begin{gathered}
\Delta E=\sqrt{\Delta L^{2}+\Delta a^{2}+\Delta b^{2}} \\
\Delta L=L-L_{0}, \Delta a=a-a_{0}, \text { and } \Delta b=b-b_{0}
\end{gathered}
$$

where $\mathrm{L}_{0}, a_{0}$ and $b_{0}$ are color values of the fresh pomace.

$$
C=\left(a^{2}+b^{2}\right)^{1 / 2} \text {. }
$$

\section{RESULTS AND DISCUSSION}

\section{A. Drying Curves}

Moisture content of apricot pomace was $4.6179 \mathrm{~kg}$ water / kg dry matter dried until about $0.05 \mathrm{~kg}$ water / kg dry matter at different powers. The effect of infrared power on drying curves of the apricot pomace is shown in Fig. 1 .

The drying curves were typical of similar agricultural products. The moisture content decreased exponentially with elapsed duration of drying and decreased faster at higher infrared powers in all cases, as expected. The drying time decreased greatly when the infrared power level increased. The drying time that required to reach the final moisture content of samples were 450, 390, 240, 180 and $150 \mathrm{~min}$ at the infrared power levels of $62,74,88,104$ and $125 \mathrm{~W}$, respectively. The average drying rate increased 3 times as the infrared power increased from 62 $\mathrm{W}$ to $125 \mathrm{~W}$. As expected at higher infrared power the higher heat absorption resulted in higher product temperature, higher mass transfer driving force, faster drying rate and consequently lesser drying time (Ponkham et al., 2012; Riadh et al., 2015; Kocabiyik et al., 2015; Doymaz, 2016).

The drying rate curves of apricot pomace are shown in Fig. 2.

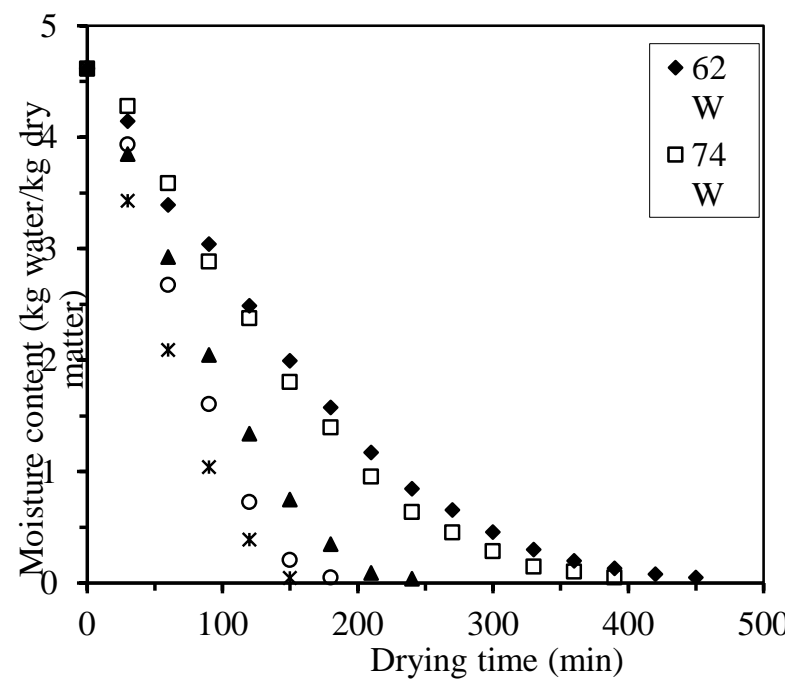

Figure 1. Drying curves of apricot pomace at different infrared powers.

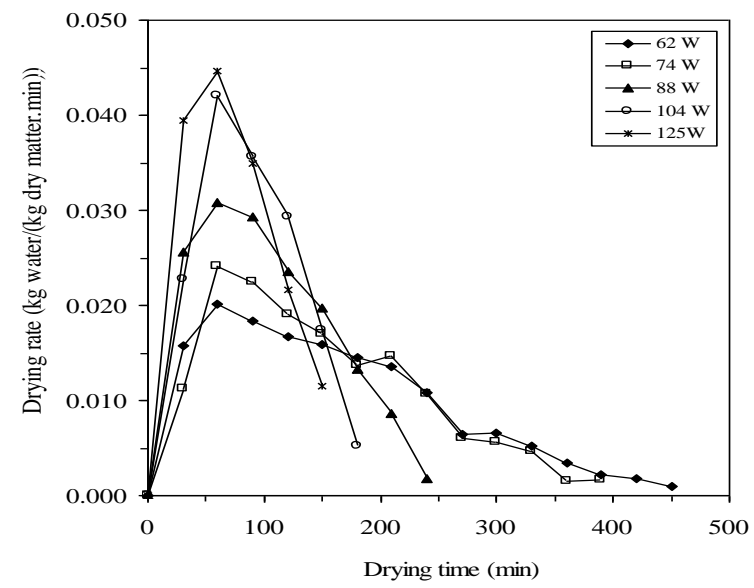

Figure 2. Drying rate vs. time for apricot pomace.

Table 1. The results of regression analysis

\begin{tabular}{clccc}
\hline Power (W) & Model coefficients & $R^{2}$ & $\chi^{2}$ & RMSE \\
\hline 62 & a: 1.078366 ; k: 0.006769 & 0.9803 & 0.002324 & 0.163180 \\
74 & a: $1.105065 ; \mathrm{k}: 0.007409$ & 0.9721 & 0.003661 & 0.193622 \\
88 & a: $1.076304 ; \mathrm{k}: 0.011117$ & 0.9658 & 0.005236 & 0.178480 \\
104 & a: $1.089134 ; \mathrm{k}: 0.013233$ & 0.9426 & 0.010677 & 0.216322 \\
125 & a: $1.052809 ; \mathrm{k}: 0.016020$ & 0.9653 & 0.006574 & 0.151906 \\
\hline
\end{tabular}

The drying rate increased with increasing air temperature. At the beginning of the drying processes, drying rate increased especially at high air temperatures due to high moisture content of the sample, where liquid vaporization took place within the sample. This creates a large vapor pressure difference between the center and the surface of products. Then, the evaporation of free water could cause the cooling of the sample and, hence, decreasing the drying rate (Horuz et al., 2018).

A constant drying rate period was not observed in all cases, all drying process took place in the falling drying rate period. Therefore, internal mass transfer resistance controls the drying time. Similar results have been reported in the literature for drying of agricultural products such as apricot (Igual et al., 2012), carrot pomace (Kumar et al., 2012), and apple pomace (Wang et al., 2007). From Fig. 2, the increase of drying rate is observed with the increase of infrared power level. This means, at high power levels the heat and mass transfer is higher and the water loss is more excessive. During drying process, the drying rates were higher in the beginning of the process, and after that decreased with decrease of moisture content in the samples. The reason for reduction of drying rate might due to reduction in porosity of samples due to shrinkage with advancement, which increased the resistance to movement of water leading to further fall in drying rates (Singh et al., 2006). The results were consistent with observations made by different authors on drying various agricultural products (Chen et al., 2015; Li et al., 2015).

\section{B. Evaluation of the Model}

The moisture content data of obtained at different infrared powers were converted into the MR and fitted to Henderson \& Pabis model (Eq. 7). Results of the statistical computing are shown in Table 1 . The values of $R^{2}$ were above 0.94 . The statistical parameter estimations showed 
that values of $\mathrm{R}^{2}, \chi^{2}$, and RMSE were ranged from 0.9426 to $0.9806,0.002324$ to 0.010677 , and 0.151906 to 0.216322 , respectively. To validate the selected model, plots of experimental MR and predicted MR by Henderson \& Pabis model are shown in Fig. 3.

Obviously, a good agreement was observed between experimental and predicted MR values. That is, the data points generally banded around a $45^{\circ}$ straight line on the plots. The prediction applying the model indicated the fact that moisture ratio values surround the straight line, which consequently demonstrates the pertinence of this model to describe drying characteristics of apricot pomaces. The Henderson \& Pabis model was also suggested by Iguaz et al. (2003).

\section{Effective Moisture Diffusivity}

The effective moisture diffusivity $\left(D_{\text {eff }}\right)$ values for different infrared power levels are calculated from Eq. (6). The $D_{\text {eff }}$ values are given in Fig. 4 and ranged from $1.67 \times 10^{-9}$ to $6.03 \times 10^{-9} \mathrm{~m}^{2} / \mathrm{s}$.

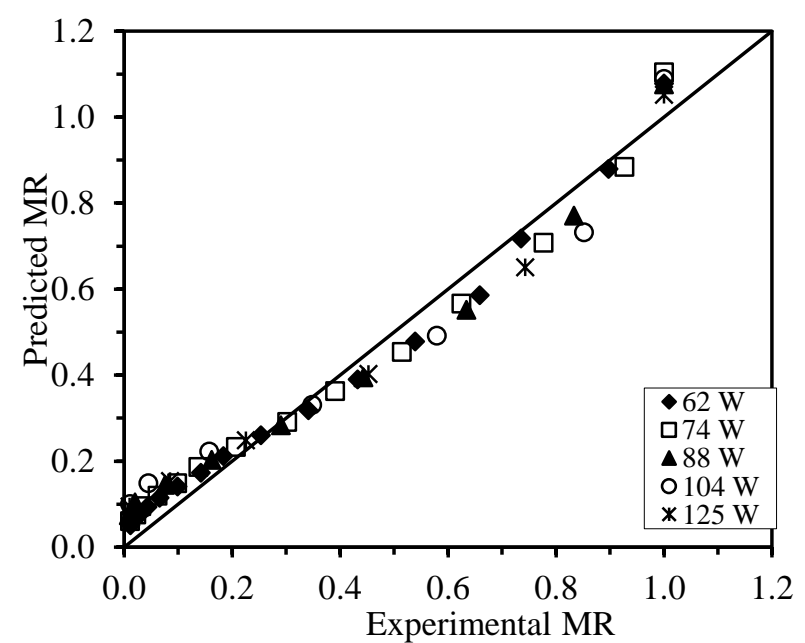

Figure 3. Experimental and predicted moisture ratio from the Henderson \& Pabis model distributions of apricot pomace

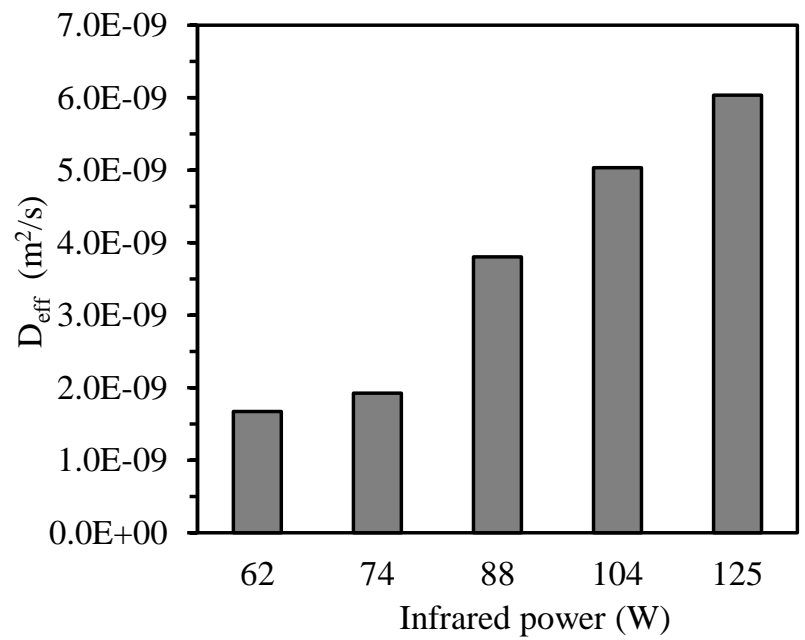

Figure 4. Effective moisture diffusivity versus infrared power.

It can be seen that values of $D_{\text {eff }}$ increased greatly with increasing infrared power level. This may be because, the increase in power level caused rapid rise in temperature of the apricot pomace, which in turn increased the vapour pressure. As result, it led to faster drying. Drying at 125 W has the highest value of effective moisture diffusivity and the lowest value was obtained for $62 \mathrm{~W}$. The $D_{\text {eff }}$ values of the apricot pomace were within the general ranges of $10^{-12}$ to $10^{-8} \mathrm{~m}^{2} / \mathrm{s}$ for biological materials (Zogzas et al., 1996). The effect of infrared power on effective moisture diffusivity is defined by the following equation:

$$
D_{\text {eff }}=1 \times 10^{-9} p+1 \times 10^{-10} \quad\left(R^{2}=0.9656\right)
$$

\section{Activation Energy}

The activation energy can be determined from the slope of Arrhenius plot, $\ln \left(D_{\text {eff }}\right)$ versus $m / p$ (Eq. 11). The $\ln$ $\left(D_{\text {eff }}\right)$ as a function of the sample weight/infrared power level was plotted in Fig. 5.

The results show a linear relationship due to Arrhenius type dependence. Equation (15) shows the effect of sample weight/infrared power on $D_{\text {eff }}$ of samples with the following coefficients:

$$
D_{\text {eff }}=2.516 \times 10^{-8} \exp \left(-\frac{2320.8 m}{p}\right) \quad\left(R^{2}=0.9468\right)
$$

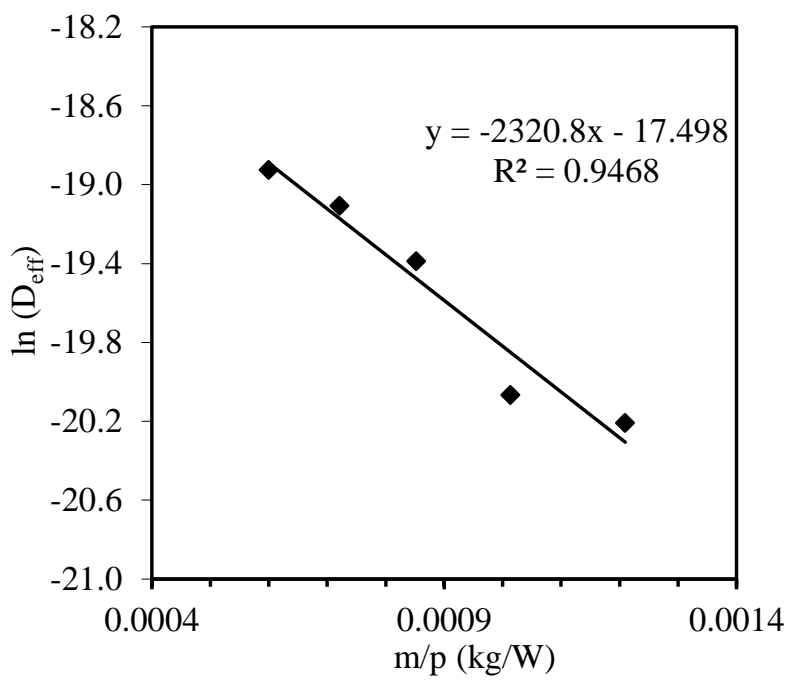

Figure 5. Arrhenius-type relationship between effective moisture diffusivity and infrared power

Table 2. The colour values of fresh and dried apricot pomaces

\begin{tabular}{cccccc}
\hline Power $(\mathrm{W})$ & $L$ & $a$ & $b$ & $\Delta E$ & $C$ \\
\hline 62 & 31.39 & 11.96 & 18.48 & 7.95 & 22.01 \\
74 & 30.78 & 11.94 & 18.62 & 8.04 & 21.60 \\
88 & 29.39 & 11.58 & 15.99 & 8.25 & 19.74 \\
104 & 25.08 & 9.62 & 13.48 & 8.77 & 16.56 \\
125 & 21.83 & 8.07 & 8.31 & 9.32 & 11.58 \\
\hline
\end{tabular}

The estimated values of $D_{0}$ and $E_{a}$ from modified Arrhenius type exponential Eq. (15) are $2.32 \mathrm{~kW} / \mathrm{kg}$.

\section{E. Colour}

Colour of dried fruits and vegetables can indicate retention of the pigment nutrients as carotenoids, flavonoids, phenols, chlorophyll and betalains (Aral and Bese, 2016). These changes of values of $\mathrm{L}, \mathrm{a}$, and $\mathrm{b}$ may be due to degradation of pigments or nonenzymatic Maillard 
browning (Garcia-Martinez et al., 2013). The colour values such as $L, a, b$ and chroma $(C)$ values for fresh apricot pomace were measured at $65.60,11.20,48.24$ and 49.52, respectively. The results of colour values obtained from the after drying processes are presented in Table 2 . The results showed that all fresh apricot pomace colour parameters $(L, a, b, \Delta E$ and $C)$ changed significantly after infrared drying. The maximum total colour change $(\Delta E)$ was $125 \mathrm{~W}$. The colour results showed that the $L, a, b$ and chroma values decreased with increasing power level. The similar results were reported by different authors on drying grape pomace (Sui et al., 2014), apricot (Ihns et al., 2011), and kiwifruit (Aidani et al., 2017).

\section{CONCLUSIONS}

The drying characteristics of apricot pomace were investigated in an infrared dryer at different infrared powers. The drying of apricot pomace at each infrared power occurred in falling-rate period. The drying time significantly decreased with the increase in infrared power. The high $R^{2}$, low $\chi^{2}$ and RMSE indicated the acceptability of Henderson and Pabis model for predicting moisture content. The effective moisture diffusivity values were varied between $1.67 \times 10^{-9}$ to $6.03 \times 10^{-9} \mathrm{~m}^{2} / \mathrm{s}$. With the increase of power level, the effective moisture diffusivity increased. Activation energy was estimated to be 2.32 $\mathrm{kW} / \mathrm{kg}$. The colour results were affected by drying conditions.

\section{REFERENCES}

Adak, N., Heybeli N. and Ertekin C. (2017) "Infrared drying of strawberry," Food Chem., 219, 109-116.

Aidani, E., Hadadkhodaparast M.and Kashaninejad M. (2017) "Experimental and modeling investigation of mass transfer during combined infrared-vacuum drying of Hayward kiwifruits," Food Sci. Nutr., 5, 596601 .

Al-Harahsheh, M., Al-Muhtaseb A.H.and Magee T.R.A. (2009) "Microwave drying kinetics of tomato pomace: Effect of osmotic dehydration," Chem. Eng. Proces., 48, 524-531.

AOAC (1990) Official Method of Analysis, Association of Official Analytical Chemists, Arlington,VA.

Aral, S. and Bese A.V. (2016) "Convective drying of hawthorn fruit (Crataegus spp.): Effect of experimental parameters on drying kinetics, color, shrinkage, and rehydration capacity," Food Chem., 210, 577-584

Calín-Sánchez, A., Figiel A., Wojdylo A., Szaryez M. and Carbonell-Barrachina A.A. (2014) "Drying of garlic slices using convective pre-drying and vacuum-microwave finishing drying: Kinetics, energy consumption, and quality studies," Food Bioprocess Technol., 7, 398-408.

Celma, A.R., Lopez-Rodriguez F. and Blazquez C. (2009) "Experimental modeling of infrared drying of industrial grape by-products," Food Bioprod. Proces., 87, 247-253.

Chen, Q., Bi J., Wu X., Yi J., Zhou L. and Zhou Y. (2015) "Drying kinetics and quality attributes of jujube (Zizyphus jujuba Miller) slices dried by hot-air and short- and medium-wave infrared radiation," $L W T$ Food Sci. Technol., 64, 759-766.

Crank, J. (1975) The mathematics of diffusion, $2^{\text {nd }}$ ed. Clarendon Press, Oxford.

Dai, J., Rao J., Wang D., Xie L., Xiao H., Liu Y. and Gao Z. (2015) "Process-based drying temperature and humidity integration control enhances drying kinetics of apricot halves," Dry. Technol., 33, 365-376.

Das, I., Das S.K. and Bal S. (2009) "Drying kinetics of high moisture paddy undergoing vibration-assisted infrared (IR) drying," J. Food Eng., 95, 166-171.

Deamici, K.M., de Oliveira L.C., da Rosa G.S. and de Oliveira E.G. (2016) "Drying kinetics of fermented grape pomace: Determination of moisture effective diffusivity," Rev. Bras. Eng. Agríc. Ambient., 20, 763-768.

Doymaz, I. (2016) "Experimental study on drying characteristics of pumpkin seeds in an infrared dryer," Latin Am. Appl. Res. 46, 167-172.

Fahloul, D., Lahbari M., Benmoussa H. and Mezdour S. (2009) "Effect of osmotic dehydration on the freeze dryig kinetics of apricots," J. Food Agric. Environ., 7, 117-121.

Garcia-Martinez, E., Igual M., Martin-Esparza M.E. and Martinez-Navarrete N. (2013) "Assessment of the bioactive compounds, color, and mechanical properties of apricots as affected by drying treatment," Food Bioprocess Technol., 6, 3247-3255.

HLPE (2014)Food Losses and Waste in the Context of Sustainable Food Systems, Rome. http://www.un.org/en/ zerohunger/pdfs/ HLPE_FLW_Report-8_EN.pdf

Henderson, S.M. and Pabis S. (1961) "Grain drying theory I: Temperature effect on drying coefficient," $J$. Agric. Res. Eng., 7, 85-89

Horuz, E., Bozkurt H., Karatas H. and Maskan M. (2018) "Simultaneous application of microwave energy and hot air to whole drying process of apple slices: drying kinetics, modeling, temperature profile and energy aspect," Heat Mass Trans., 54, 425-436.

Igual, M., García-Martínez E., Martín-Esparza M.E. and Martínez-Navarrete N. (2012) "Effect of processing on the drying kinetics and functional value of dried apricot," Food Res. Int., 47, 284-290.

Iguaz, A., San Martin M.B., Mate J.I., Fernandez T. and Virseda P. (2003) "Modelling effective moisture diffusivity of rough rice (Lido cultivar) at low drying temperatures", J. Food Eng., 59, 253-258.

Ihns, R., Diamante L.M., Savage G.P. and Vanhanen L. (2011) "Effect of temperature on the drying characteristics, colour, antioxidant and beta-carotene contents of two apricot varieties," Int. J. Food Sci. Technol., 46, 275-283

Kocabiyik, H., Yilmaz N., Tuncel N.B., Sumer S.K. and Buyukcan M.B. (2015) "Drying, energy, and some physical and nutritional quality properties of tomatoes dried with short-infrared radiation," Food Bioprocess Technol., 8, 516-535. 
Kumar, N., Sarkar B.C. and Sharma H.K. (2012) "Mathematical modelling of thin layer hot air drying of carrot pomace," J. Food Sci. Technol., 49, 33-41

Li, Z.L., Chen Q.Q., Bi J.F., Wu X.Y., Duan Y.Q. and Si X., (2015) "Effects of combined convective-infrared radiation on quality of mulberries," Modern Food Sci. Technol., 31, 166-172.

Martynenko, A. and Kudra T. (2016) "Electrohydrodynamic (EHD) Drying of grape pomace,",Japan J. Food Eng., 17, 123-129.

Moses, J.A., Norton N., Alagusundaram K. and Tiwari B.K. (2014) "Novel drying techniques for the food industry," Food Eng. Rev., 6, 43-55.

Motevali, A., Minaei S., Khoshtaghaza M. and Amirnejat H.H. (2011) "Comparison of energy consumption and specific energy requirements of different methods for drying mushroom slices," Energy, 36, 6433-6441.

Oberoi, D.P.S. and Sogi D.S. (2015) "Drying kinetics, moisture diffusivity and lycopene retention of watermelon pomace in different dryers," J. Food Sci. Technol., 52, 7377-7384.

Pawar, S.B. and Pratape V.M. (2015) "Fundamentals of infrared heating and its application in drying of food materials: A review," J. Food Process Eng., 40, e12308.

Ponkham, K., Meeso N., Soponronnarit S. and Siriamornpun S. (2012) "Modeling of combined far-infrared radiation and air drying of a ring shaped-pineapple with/without shrinkage," Food Bioprod. Proces., 90, 155-164.

Riadh, M.H., Ahmad S.A.B., Marhaban M.H. and Soh A.C. (2015) "Infrared heating in food drying: An overview," Dry. Technol., 33, 322-335.
Ribeiro, L.F., Ribani R.H., Francisco T.M.G., Soares A.A., Pontarolo R. and Haminiuk C.W.I. (2015) "Profile of bioactive compounds from grape pomace (Vitis vinifera and Vitis labrusca) by spectrophotometric, chromatographic and spectralanalyses," $J$. Chromatography B, 1007, 72-80.

Singh, B., Panesar P.S. and Nanda V. (2006) "Utilization of carrot pomace for the preparation of a value-added product," World J. Dairy Food Sci., 1, 22-27.

Stancu, V., Haugaard P. and Læhteenmæki L. (2016), "Determinants of consumer food waste behaviour: Two routes to food waste," Appetite, 96, 7-17.

Sui, Y., Yang J., Ye Q., Li H. and Wang H. (2014) "Infrared, convective, and sequential infrared and convective drying of wine grape pomace," Dry. Technol., 32, 686-694.

Ucuncu, C., Tari C., Demir H., Buyukkileci A. and Oguz O.B. (2013) "Dilute-acid hydrolysis of apple, orange, apricot and peach pomaces as potential candidates for bioethanol production," J. Biobased Mater. Bioenergy, 7, 376-389.

Wang, Z., Sun J., Liao X., Chen F., Zhao G., Wu J. and $\mathrm{Hu}$ X. (2007) "Mathematical modeling on hot air drying of thin layer apple pomace," Food Res. Int., 40, 39-46.

Zogzas, N.P., Maroulis Z.B. and Marinos-Kouris D. (1996) "Moisture diffusivity data compilation in foodstuffs," Dry Technol., 14, 2225-2253.

Received. July 11, 2017

Sent to Guest Editor. January 31, 2018

Accepted. June 27, 2019

Recommended by Guest Editor Marcelo Seckler 